\title{
Para além da descrição da diferença: apontamentos sobre o método da roleta interseccional para estudos em Comunicação
}

\author{
Beyond the description of difference: notes on the intersectional \\ roulette method for communication studies
}

\begin{abstract}
Fernanda Carrera a,*
RESUMO: Este trabalho visa aprofundar o debate sobre o método da roleta interseccional para estudos em Comunicação, compreendendo que a proposta aciona categorias e marcadores da diferença (gênero, raça, classe, idade, sexualidade, peso, geolocalização e deficiência) distintos, complexos e em reiterada disputa. Ao compreender que a articulação de diferentes avenidas identitárias mobiliza profundos debates a respeito, inclusive, dos seus fundamentos sociológicos e culturais, a proposição interseccional não somente os reconhece como é constituída por estes pressupostos, reivindicando análises em conformidade com a complexidade dos marcadores e das suas estruturas de opressão. Propõe-se aqui, portanto, ampliar a discussão sobre a roleta interseccional, articulando saberes e etapas analíticas importantes para a sua aplicabilidade, bem como esboçar a silhueta de uma análise de objeto comunicacional - movimento Body Positive no Instagram - a partir deste projeto metodológico.
\end{abstract}

Palavras-chave: Interseccionalidade; Comunicação; Metodologia; Roleta interseccional.

ABSTRACT: This paper aims to deepen the debate about the method of intersectional roulette for studies in Communication, understanding that the proposal triggers categories and markers of difference (gender, race, class, age, sexuality, weight, geolocation and disability) that are distinct, complex and in repeated dispute. By understanding that the articulation of different identity avenues mobilizes profound debates regarding, among other things, their sociological and cultural foundations, the intersectional proposition not only recognizes them but is also constituted by these assumptions, claiming analyses in conformity with the complexity of the markers and their structures of oppression. It is proposed here, therefore, to expand the discussion on intersectional roulette, articulating important knowledge and analytical steps for its applicability, as well as sketching the silhouette of a communicational object analysis - Body Positive movement on Instagram - from this methodological project.

Keywords: Intersectionality; Communication; Methodology; Intersectional Roulette.

\footnotetext{
a Escola de Comunicação, Universidade Federal do Rio de Janeiro, Rio de Janeiro, RJ, Brasil.

*Correspondência para/Correspondence to: Fernanda Carrera. E-mail: fernanda.carrera@eco.ufrj.br.

Recebido em/Received: 25/06/2021; Aprovado em/Approved: 03/11/2021.
}

Artigo publicado em acesso aberto sob licença CC BY 4.0 Internacional $@()$ 


\section{A ROLETA INTERSECCIONAL: APONTAMENTOS PARA APLICABILIDADE}

Se a perspectiva interseccional já é cara aos estudos em Comunicação, sobretudo aqueles interessados nos efeitos da opressão sobre sujeitos marcados pelos limites existenciais em gênero, raça e classe, ainda há lacunas importantes nas análises que se permitem ir além da descrição das diferenças. De que modo é possível ultrapassar as dimensões descritivas dos objetos comunicacionais, localizando-os em conjunturas complexas de impactos, respostas e redirecionamentos? A proposta da roleta interseccional é uma tentativa de assumir este desafio metodológico, reconhecendo que a complexidade da constituição das subjetividades deve ser um alvo científico generalizado. Aliando a roleta, que perpassa por hastes representativas de avenidas identitárias fundamentais (gênero, raça, classe, peso, idade, deficiência, geolocalização e sexualidade), à metáfora da combinação das cores, a proposição metodológica da roleta interseccional busca evitar a negligência de alguma interseção indispensável para a composição e para a análise dos objetos (Carrera, 2020)1.

Nesse sentido, faz-se relevante não somente definir e expor os parâmetros para a composição da roleta interseccional, como tentar avançar no debate sobre seus fundamentos e conexões interdisciplinares, sobretudo no que tange à etapa de aprofundamento das categorias identitárias, representada na proposta pela descrição da formação interseccional-discursiva, do ethos e das negociações interseccionais. Além disso, se já houve tentativa de ilustrar a aplicação do método para análise de objetos comunicacionais (Martins e Carrera, 2020), aqui a intenção é aprofundar este debate com a exposição detalhada dos processos necessários à aplicabilidade da roleta para resultados de análise satisfatórios. O primeiro passo, então, é a compreensão de que todo estudo que se permite empregar o pensamento interseccional toca no compromisso de ser comparativo, complexo e congruente ao "ethos de justiça social" (Collins, 2017, p. 15), sem receio de atender ao enredamento subjetivo que envolve indivíduos submetidos a dinâmicas de opressão a partir de perspectivas interdisciplinares.

A ordem comparativa mobilizada pela roleta interseccional visa se conectar aos princípios do conceito de interseccionalidade pensado por Crenshaw (1989), que teve como ímpeto inicial a busca por justiça no sistema penal estadunidense. Esta inclinação comparativa serve à compreensão, inclusive, da heterogeneidade de cada marcador social da diferença. A idade, por exemplo, é um importante complexificador das experiências sociais de mulheres negras jovens e mulheres negras idosas, uma vez que não somente revela a diversidade das vivências de gênero e raça, como, muitas vezes, mostra que as experiências podem ser impactadas por simbologias radicalmente

\footnotetext{
${ }^{1}$ Sobre a proposta, ver: "Roleta interseccional: proposta metodológica para análises em Comunicação". E-Compós. Disponível em: https://www.e-compos.org.br/ecompos/article/view/2198
} 
opostas. Enquanto mulheres negras jovens sofrem os efeitos da "imagem de controle" da Jezebel (Collins, 2002, p. 99), que corresponde à depravação, hiperssexualização e disponibilidade sexual (Carneiro, 1995); mulheres negras mais velhas sofrem os efeitos da imagem de controle da mãe preta (Gonzalez, 1988), que gira em torno da total assexualidade e silenciamento, do serviço doméstico e cuidado de pessoas brancas. As duas, portanto, experienciam racismo e sexismo em alta potência e são impactadas por modos de percepção opostos, mas sob a mesma estrutura de opressão.

Por sua vez, em situação comunicacional que envolve oralidade, é impossível negligenciar o impacto da geolocalização para o entendimento dos lugares que os sujeitos ocupam e nas relações de poder que exercem entre si. No Brasil, pessoas negras estrangeiras podem acionar lugares de privilégio e vantagem, a depender do cenário, pela lógica da colonialidade que direciona muitas práticas e discursos vigentes aqui. Além disso, não se pode subestimar os impactos dos colonialismos internos (Quijano, 2002), que transformam as experiências e as dinâmicas de opressão vivenciadas por pessoas negras nortistas e nordestinas quando estão localizadas em estados que representam o lócus do poder econômico brasileiro. Os mesmos sujeitos, portanto, podem protagonizar situações comunicacionais diversas, tanto de opressão quanto de privilégio, a depender da conjuntura que se estabelece ao seu redor. Nesse sentido, o método admite que não há hierarquia de opressões, mas conjunturas relacionais que definem o funcionamento e os efeitos das estruturas.

Dentro dessa perspectiva, a análise interseccional é, por definição, um manifesto para o reconhecimento das opressões e dos privilégios que acometem as diferenças. A intenção dos estudos em Comunicação é, portanto, perceber as marcas destas flutuações e negociações na materialidade, nos processos e nas práticas comunicacionais, revelando como estes espaços também podem ser lugares de reforço e manutenção de desigualdades sociais. Nesse sentido, este é o ethos de justiça social que cabe aos esforços analíticos em Comunicação, entendendo que a área é intensamente tocada por outras disciplinas e seus pressupostos. Nesse sentido, o objetivo da interdisciplinaridade na roleta interseccional, então, é a busca pela compreensão aprofundada dos princípios, das disputas e das implicações que envolvem cada avenida identitária.

\section{SOBRE OS APROFUNDAMENTOS ACERCA DAS CATEGORIAS SOCIAIS}

O método proposto pela roleta interseccional pressupõe duas etapas fundamentais. Se a primeira constrói a silhueta do objeto analisado a partir de oito categorias fundamentais (gênero, raça, classe, sexualidade, deficiência, peso, geolocalização e idade), a segunda fase é o estudo da complexidade que envolve cada marcador relevante para o objeto e de seus atravessamentos e interseções. Dessa forma, se o primeiro momento envolve um processo descritivo das diferenças e dos traços evidenciados na análise, o segundo permite o aprofundamento necessário ao estudo interseccional (ver figura 1). 
Figura 1. As duas etapas da Roleta Interseccional - método para análises em Comunicação (Carrera, 2020)

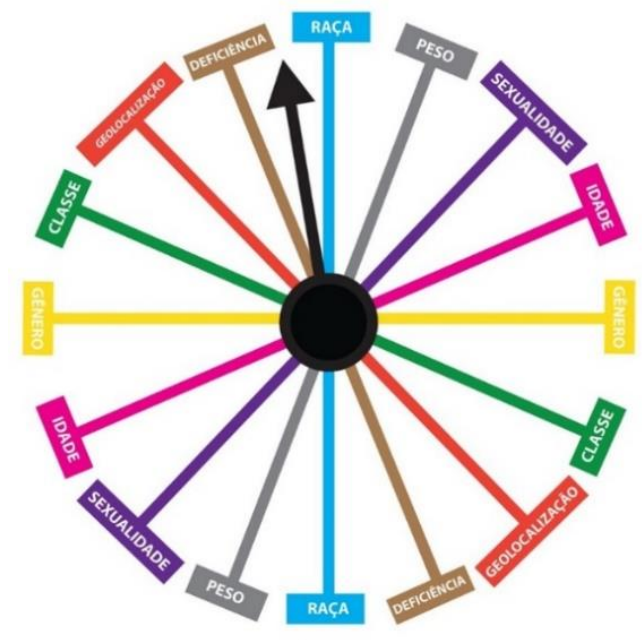

Etapa 1 a) Formação interseccionaldiscursiva

b) Ethos interseccional

c) Negociações interseccionais

Etapa 2

O método, então, reconhece a importância da identificação, por exemplo, de um objeto de análise atravessado pelas opressões de gênero, raça e classe, mas estimula que a pesquisa aprofunde o entendimento sobre as disputas, os pressupostos e delineamentos que regem estes marcadores em um dado contexto sociocultural e histórico, assim como os imperativos, os silenciamentos e os fatores impositivos, inclusive para o desenvolvimento do conhecimento sobre o tema. Todos estes fatores são a baliza para a construção da formação interseccional-discursiva (conjuntura sociocultural e histórica que demarca os limites das existências), do ethos interseccional (que se constrói a partir dos atravessamentos identitários) e das negociações interseccionais, que se estabelecem na interação.

Se gênero, então, é uma haste fundamental para o objeto estudado (iluminada na primeira etapa da pesquisa), é imprescindível entender quais os efeitos dessa diferença que rasuram e deixam marcas na materialidade (processo que acontece na segunda etapa da análise). Isto é, não somente de que gênero estamos falando, mas de qual entendimento sobre gênero o objeto fala? Dessa forma, além de ser essencial entender as limitações da construção social da identidade de gênero, como propõe Beauvoir (2014), é fundamental considerar a dimensão performática de gênero (Butler, 2010) acionada pelo objeto. São caros à problematização de gênero, então, os avanços permitidos pelos estudos feministas, mas também aqueles que se debruçam sobre as concepções de masculinidades; sobre os efeitos da cisgeneridade compulsória e da cisnormatividade, pensados pelos transfeminismos e pelas teorias queer; assim como os entrelaçamentos inevitáveis da categoria com outras diferenças, como raça, classe, sexualidade e geolocalização (Anzaldúa, 1987). Estes contatos, aliás, não somente são impossíveis de negligenciar em todas as categorias, como são imprescindíveis para a análise interseccional. 
A raça, na metodologia interseccional da roleta, é quase inevitável em qualquer estudo em Comunicação. Alguns objetos, no entanto, sobretudo aqueles que recorrem à invisibilidade racial permitida pela neutralidade associada à branquitude (Schucman, 2012), são marcados racialmente por este silenciamento. Nesse sentido, as ausências também são rastros importantes nos objetos analisados, revelando que a potência da racialidade acomete corpos tanto por dinâmicas de opressão quanto de privilégios. Perceber de que forma a estrutura do racismo opera sobre os sujeitos, até mesmo nas gradações da pigmentocracia ou colorismo (Devulsky, 2021), é fundamental tanto na delimitação dos processos de construção identitária, quanto naqueles de representação e de práticas de violência (Do Nascimento, 2016). Na metodologia da roleta interseccional, é essencial localizar de que forma a racialização é implicada no objeto, seja pelas escolhas discursivas, pelas marcações identitárias como pelos comportamentos sociais empreendidos.

Aliada a noções de raça e gênero, classe fecha a tríade conceitual mais comum nos estudos em comunicação e interseccionalidade (Collins, 2017), especialmente pela consistência do debate desde a perspectiva marxista e suas reverberações nas ciências sociais aplicadas. Ao reconhecer a classe como marcador fundamental na construção das subjetividades e dos limites simbólicos que perpassam as análises comunicacionais, é preciso, no entanto, atestar que este marcador opera como estrutura fundamental atravessada e impregnada por outras diferenças. Isto é, há modos de exploração que ultrapassam a dimensão econômica e não podem ser explicados apenas a partir desta inscrição de desigualdade (Gonzalez, 2018). Para a Comunicação, entretanto, perceber a influência da classe na construção dos sentidos é compreendê-la como fundamental tanto para os limites interacionais que estabelece quanto para as apropriações dos sujeitos a partir da linguagem e dos comportamentos sociais. Classe, então, "permanece como uma força essencial para modelar a maneira como vivemos hoje" (Murdock, 2009, p. 33), sendo inevitável reconhecer que "as marcas das classes e das lutas de classes se encontram nas relações de comunicação. Pois sim, a comunicação tem classes" (Grohmann, 2016, p. 306).

$\mathrm{Na}$ construção da roleta interseccional, as sexualidades também são reivindicadas como categoria importante para a compreensão das escolhas comunicacionais. Tocada pelas perspectivas de gênero, muitas vezes a sexualidade é confundida e mergulhada em seus pressupostos, carecendo de olhar específico sobre suas implicações identitárias e interacionais. Ao considerar o debate ampliado e consolidado sobre a dimensão do desejo (Foucault, 1988), entende-se aqui a importância de fugir de essencialismos que visam a biologização da sexualidade, uma vez que as dimensões políticas do sexo e as disputas de poder que envolvem os caminhos do desejo sexual podem ser definitivas para a construção do sujeito pensado na Comunicação. Nesse sentido, é crucial compreender os efeitos da heterossexualidade nas marcações comunicacionais, produzindo índices da cultura heteronormativa que define os contornos discursivos de um corpo legitimado; assim como entender de que forma são construídas as homoafetividades, lesbianidades e assexualidades, compondo minorias sexuais (Vieira, 2012) e modos de comunicação que podem ser imprescindíveis para o entendimento do objeto e do sujeito analisado. 
Na direção da legitimação do corpo, três hastes representam matrizes de opressão essenciais para a produção de uma análise interseccional: peso, deficiência e idade. 0 corpo, nessas categorias, representa um papel fundamental na construção dos estigmas associados aos sujeitos, sendo considerado, muitas vezes, por si só "um defeito, uma fraqueza, uma desvantagem - e constitui uma discrepância específica entre a identidade social virtual e a identidade social real" (Goffman, 1988, p. 6). Corpo gordo, corpo com deficiência e velhice, portanto, são lugares de marginalização que operam em lócus extremos de opressão social, representando tanta importância quanto aqueles que envolvem dinâmicas de gênero, raça, classe e sexualidade. No entanto, o debate acerca destas categorias ainda representa uma lacuna importante nas análises interseccionais em Comunicação.

O corpo gordo sofreu transformações radicais a respeito dos seus significados sociais dentro da expectativa ocidental. Atualmente atrelado a fracasso estético, não somente é nesse domínio que opera a repressão ao sujeito gordo, aliás, o fundamento da gordofobia como parâmetro de opressão é a marginalização e a propagação do sentimento de inadequação social: "Os lugares públicos não acolhem os gordos: das poltronas, roletas de ônibus e catracas de metrôs às portas giratórias dos bancos” (Aires, 2019, p.27). Nesse sentido, o sujeito gordo sente a exclusão social no plano estético, no âmbito do trânsito social e, inclusive no acesso a direitos fundamentais, uma vez que há patologização do corpo gordo por meio da construção da doença da obesidade.

No campo da representação midiática, cara aos estudos em Comunicação, o corpo gordo, uma vez que foge da normatividade arbitrária da cultura, é localizado no plano do humor: "os gordos costumam parecer ridículos" (Maranho e Contiero, 2008, p. 10). Se não é relegado ao lugar do riso, o sujeito gordo está ligado simbolicamente ao malestar e ao isolamento social. Estas associações são construídas pelos discursos da oralidade, mas, também, reforçadas pelas imagens midiáticas, jornalísticas e publicitárias. É, portanto, fundamental reconhecer que o peso ${ }^{2}$ adquire, na conjuntura sociocultural e histórica, um lugar significativo na produção das subjetividades, uma vez que constrange os limites possíveis de existência e desloca o sujeito da normatividade para a marginalização. Atravessado por outras avenidas de opressão, o peso, então pode adquirir valores diferenciados na produção dos caminhos subjetivos do indivíduo: mulheres gordas e homens gordos, por exemplo, ocupam lugares diversos no plano das expectativas sociais e dos estigmas associados. É relevante considerar estes entrecruzamentos e reconhecer a importância dessa categoria para a formação subjetiva dentro de uma análise interseccional.

\footnotetext{
2 Peso, na roleta interseccional, é termo escolhido para designar os parâmetros através dos quais o corpo é considerado gordo ou magro. Nesse sentido, não se pensa peso aqui a partir da categorização médico-científica do índice de massa corpórea, mas a partir da percepção social do peso que adquire sentidos de sucesso ou fracasso. O plano da percepção, então, é aquele que localiza o corpo em um dos polos da adequação, variando e fazendo flutuar sua potência a depender da situação social. Este plano, portanto, é o que interessa de forma mais imediata ao domínio da Comunicação.
} 
No plano da estigmatização social, o corpo com deficiência também ocupa lugar sob extrema opressão social. Se ao corpo gordo são conectados símbolos de insucesso e derrota, ao corpo com deficiência são somados a estes os sentidos de incapacidade inata, sofrimento, pena e necessidade de superação. A deficiência, portanto, aprisiona o sujeito "na rede das significações sociais, com seu rol de consequências, como atitudes, preconceitos, estereótipos, o que acaba por legitimar a diferença e, consequentemente, a exclusão" (Fernandes e Denari, 2017, p. 79). A cada deficiência, são encontrados modos diferenciados de discriminação, embora todos restrinjam o sujeito à subalternidade: “A fluidez e a dinamicidade afirmadas como inerentes aos processos de constituição identitária são postas em xeque pelas amarras do deficiente, estigmatizado às características de sua deficiência" (Magalhães e Cardoso, 2010, p. 59).

No domínio comunicacional e, especificamente da publicidade, por exemplo, é comum perceber ainda que, na existência de anúncios dirigidos ao público (o que é quase nulo), as diferenças são apagadas, representando as deficiências como se fossem todas iguais, assim como, muitas vezes, as iniciativas ajudam a corroborar com os estigmas sociais e exploram a "venda da piedade" (D'antino, 2001, p. 66), em um processo de comercialização da linguagem capacitista. É comum, portanto, nos produtos midiáticos, a construção da pessoa com deficiência como "inútil, incapaz para o trabalho, carente, isolado, assexuado" (Kuhn, 2005, p. 65).

Ainda no plano visível das corporeidades, o envelhecimento deve ser reconhecido como lugar importante para complexificação dos objetos de análises comunicacionais. De acordo com Palacios (2004, p. 5), o universo discursivo da publicidade, por exemplo, ajuda a difundir uma percepção negativa a respeito do fenômeno do envelhecimento: "a de que este processo é sinônimo de decrepitude". Isto é, anúncios em sua maioria representam a velhice como uma época "sombria, decrépita, repleta de temores da morte, de acometimento de doenças, que culmina com o isolamento do indivíduo dos processos de socialização, em sua fase final de vida" (Palacios, 2004, p. 2). Nesse sentido, em análises interseccionais, é essencial e "mais do que necessário reconhecer a dimensão sociocultural da velhice” (Castro, 2015, p. 104). Atravessada por outras matrizes de opressão, a velhice ainda pode significar lugares mais potentes de marginalização e, inclusive, de abreviação da vida. A classe, portanto, é um destes entrecruzamentos cruciais: "Não existe uma velhice, mas velhices, no plural (...). Há corpos desgastados por trabalhos braçais, diferentes de corpos que puderam ser cuidados (Gelehrter, 2020, p. 28). Nesse sentido, a velhice é sempre relacional, variável e produzida nos planos das percepções interacionais e interseccionais.

Por fim, a haste da geolocalização, embora não seja materializada apenas no corpo, é por meio dele que também se manifesta no domínio comunicacional, traduzida na oralidade, nos modos de interação, no âmbito do comportamento e nas relações com os outros. Nesse sentido, é relevante para a análise interseccional em Comunicação o entendimento da geopolítica dos corpos e dos sujeitos, localizando as nuances interacionais que delimitam quem pode e como se pode existir. Nesse sentido, é relevante perceber os efeitos da colonialidade em processos interacionais que deixam escapar a percepção dicotômica dos "primitivos" e dos "modernos" (Quijano, 2002), 
denunciando dinâmicas de estigmatização, preconceito linguístico e estereotipia que podem direcionar os princípios comunicacionais. No domínio midiático, esta problematização é fundamental para localizar tanto análises de representação caricatural quanto de modos de hierarquização da linguagem e, consequentemente, dos sujeitos (Pelinson, 2016).

Na segunda etapa da metodologia da roleta interseccional, portanto, é fundamental compreender de modo aprofundado as disputas impregnadas nas categorias sociais, tanto aquelas que se traduzem em embates interacionais e simbólicos - importantes para as dinâmicas de sociabilidade e conversação - quanto aquelas que se materializam em negociações e ajustes conceituais - caros aos processos teórico-científicos. Nesse contexto, o alvo analítico é o aprofundamento do estudo interseccional, tanto na dimensão da formação discursiva que envolve estes marcadores quanto no âmbito da influência das materialidades nas dinâmicas de comunicação social. Materialidades, então, assim como conflitos e debates em torno das diferenças, são essenciais para a compreensão do todo contextual que envolve os sujeitos e os corpos na pesquisa interseccional em Comunicação.

\section{ESBOÇO DE ANÁLISE COMUNICACIONAL A PARTIR DA ROLETA INTERSECCIONAL: MOVIMENTO BODY POSITIVE NO INSTAGRAM}

Com o intuito de esboçar a silhueta de análise a partir da roleta interseccional, propõese aqui um estudo elementar e comparativo em plataforma digital, debruçando-se sobre o Instagram e sobre o fenômeno das influenciadoras digitais, especialmente aquelas que representam e aplicam os fundamentos do movimento Body Positive. Articulado como um desdobramento do fat liberation movement e do fortalecimento do movimento feminista (Cwynar-Horta, 2016), o Body Positive se alicerça pela aceitação e valorização de corpos marginalizados, sobretudo aqueles que apresentam marcas visíveis da sua diferença - gordos, com deficiência, com cicatrizes ou marcas de envelhecimento, racializados. No entanto, sua raiz de movimento social em prol da liberação do corpo gordo aponta, em geral, para uma predominância deste marcador na reivindicação e aplicação do termo.

No Instagram, embora o movimento ganhe ares de comodificação pela própria lógica da plataforma, ainda há manifestações em concordância com a perspectiva do Body Positive enquanto movimento tanto individual (no incentivo à construção de autoestima pela exposição de si) quanto coletivo, quando serve à produção de conhecimento e formação de rede de colaboração e apoio. No entanto, é interessante perceber que a construção do discurso de aceitação entremeado pelos princípios do movimento Body Positive é impactada pelos entrecruzamentos identitários caros à análise interseccional. Sendo assim, é possível perceber marcas destas interseções nas escolhas comunicacionais que se estabelecem ali, entendendo que sujeitos se apropriam das materialidades e das tecnologias a partir das suas construções de sentido e de experiência. 
Para ilustrar esse pensamento, opta-se aqui por analisar os perfis no Instagram das influenciadoras Raissa Galvão (@rayneon)e Érica Almeida (@negritaalmeida), ambas com propostas coerentes com o movimento Body Positive ao mobilizarem discursos de "desconstrução de padrões", "autocuidado" e "amor interno"; e ao marcarem seus corpos gordos como enfoque comunicacional na plataforma (ver figura 2). Nesse sentido, o primeiro giro da roleta interseccional, que nesse caso engloba a análise da superfície discursiva dos perfis e os elementos mais evidentes ali expostos, ilumina rapidamente a haste do peso nas duas, no entanto cada uma mobiliza outros marcadores essenciais, como será visto aqui.

Figura 2. Influenciadoras digitais Raissa Galvão (@rayneon)e Erica Almeida (@negritaalmeida) no Instagram.
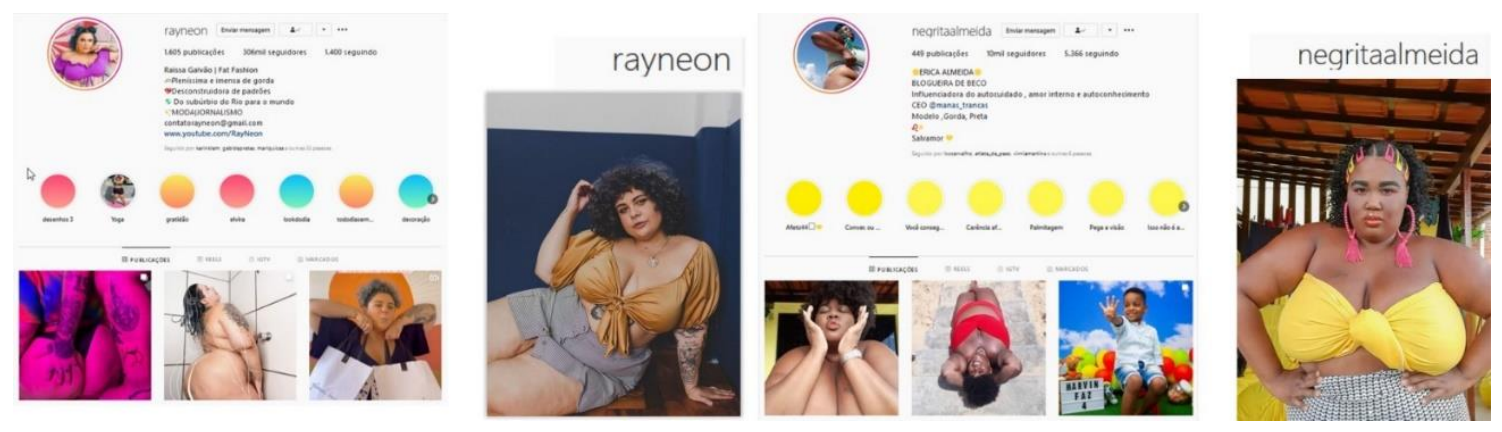

O primeiro giro da roleta interseccional, portanto, representa o olhar inicial sobre o objeto de pesquisa, seguido por quantos giros forem necessários a partir da escolha metodológica. No caso dos perfis de Instagram, a análise tanto pode se debruçar sobre o todo generalizado e imagético que compõe a identidade visual construída na plataforma, como pode adentrar em análises de conteúdos específicos, como determinados posts, vídeos, imagens, carrosséis, stories, destaques etc.; assim como de temporalidades estipuladas (publicações mais recentes ou mais antigas, por exemplo). Nos dois perfis aqui analisados, optou-se por considerar que o primeiro giro da roleta toca, de modo exploratório, na descrição (bio), nos títulos dos destaques e nas 30 primeiras publicações.

Raissa (@rayneon), então, ilumina neste primeiro giro as hastes de peso, gênero, geolocalização e classe, enquanto Érica (@negritaalmeida) ilumina as hastes de peso, raça, gênero, geolocalização e classe. Todos estes marcadores são iluminados apenas na análise da superfície dos seus conteúdos, ou seja, é evidente que o estudo de conteúdos específicos pode fazer outras hastes se iluminarem e se tornarem relevantes para o entendimento das construções de sentido que ali se estabelecem. Para fins apenas de esboço analítico, este único giro ajuda a ilustrar a proposta metodológica.

A roleta interseccional, portanto, na análise do perfil de Raissa Galvão, ilumina a haste do peso tanto na sua inscrição corpórea por meio das imagens quanto nos enunciados "Fat Fashion" e "imensa de gorda”, que compõem a sua descrição. É simples também identificar as marcações de gênero na utilização de pronomes e nas flexões das 
palavras (imensa, gorda, pleníssima); de geolocalização, quando enuncia "do subúrbio do Rio para o mundo" e deixa claro que vem da cidade do Rio de Janeiro; e de classe, no mesmo enunciado, pela escolha de atestar o subúrbio como sua localização original. No perfil de Érica Almeida (@negritaalmeida), a roleta ilumina a haste do peso e da raça também a partir das imagens de si e da sua descrição, quando enuncia "Modelo, Gorda, Preta". As marcações de gênero também são evidentes pelas flexões das palavras e na sua autodenominação, assim como dá pistas de raça pelo seu usuário (@negritaalmeida). Érica ilumina a geolocalização a partir da expressão "Salvamor", em referência à cidade de Salvador-BA; e classe, quando enuncia "Blogueira de Beco".

A partir da descrição das hastes iluminadas, então, parte-se para a segunda etapa da análise, que discute sobre a formação-discursiva interseccional das categorias mobilizadas, assim como o ethos interseccional e as negociações interseccionais possibilitadas, inclusive, pela materialidade comunicacional do Instagram.

\section{Formação interseccional-discursiva}

Quais os imperativos de gênero e os silenciamentos de gênero que Raissa e Érica estão assujeitadas? É fundamental realizar a contextualização e o aprofundamento da conjuntura sociocultural, simbólica, das hastes que se iluminaram no giro da roleta interseccional. No momento da análise aqui empreendida (fevereiro/março de 2021), pôde-se perceber que, no perfil de Raissa, há acionamento de questões caras à discussão de gênero, como casamento e noivado, vestimentas, problemáticas do uso de sutiã etc., isto é, questões que são tensionadas na perspectiva sobre o que é ser mulher e o que é legítimo nesta identificação de si enquanto mulher. É importante compreender, por exemplo, a conjuntura sociocultural na qual pedido de casamento e relacionamento afetivo em si se tornam importantes marcadores dos imperativos de gênero. A escolha pela exposição destes acontecimentos e o entendimento da relevância que estes conteúdos têm para sua audiência são indicadores do lugar que Raissa ocupa dentro desse marcador. Ademais, esses rastros de gênero em suas publicações dialogam com o seu silenciamento racial, localizando de forma mais precisa a que noção de gênero Raissa pertence. Tanto relacionamento, casamento, quanto, sobretudo, questões como transição capilar (ver figura 3) poderiam adquirir enfoques de gênero diferenciados a depender da iluminação ou não desta haste da raça na roleta interseccional. 
Figura 3. Índices de silenciamento racial coerentes com a percepção de neutralidade da branquitude no perfil de @rayneon no Instagram.
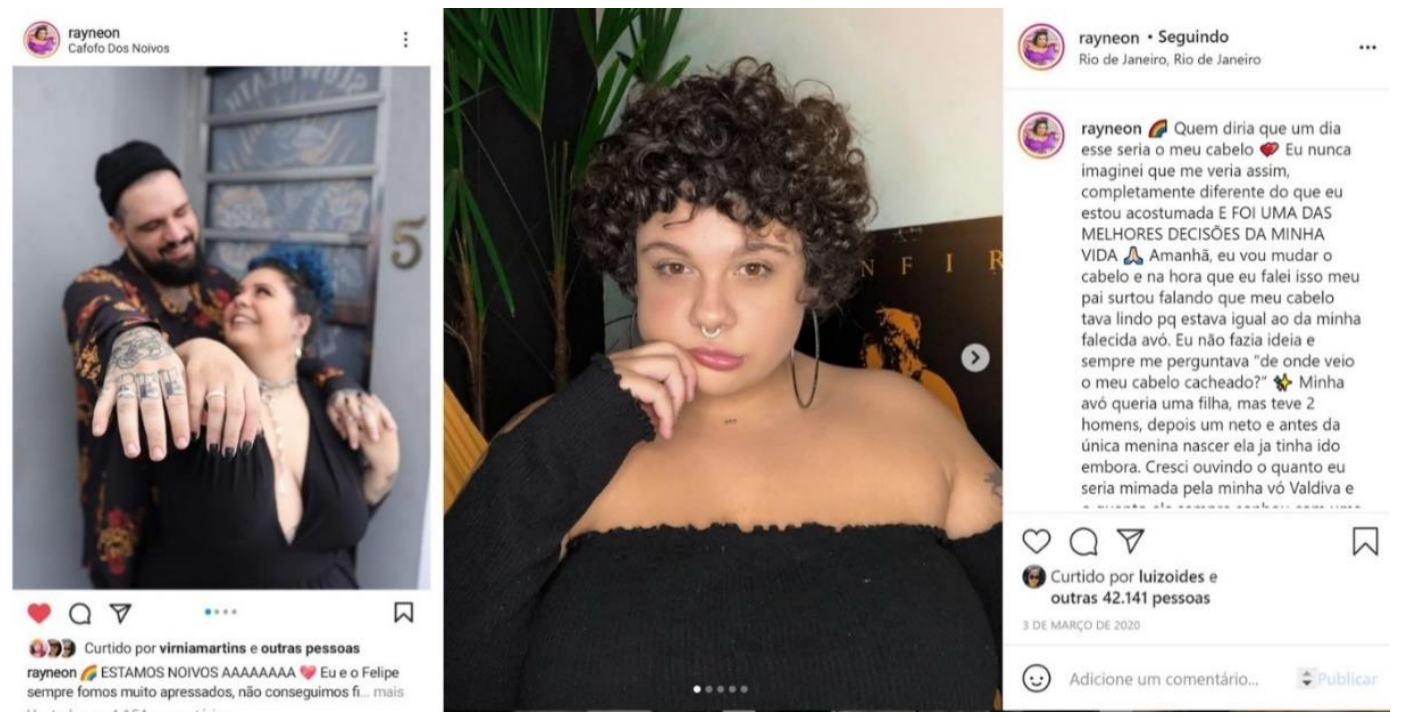

Érica também é atravessada por questões de gênero, pautando seus conteúdos também em torno de autoestima, relacionamentos, experiências de opressão de gênero, mas que são extremamente tocadas por questões raciais. Dificilmente Érica toca em problemáticas de gênero sem marcar sua racialidade, uma vez que sua experiência de gênero é racializada (ver imagem 4). Nesse sentido, o lugar de gênero que Érica ocupa é fundamentalmente diferente do lugar de gênero ocupado por Raissa, sobretudo pelo entrecruzamento de raça na construção das duas subjetividades.

Além disso, vale dizer que os apontamentos de Érica para questões de raça também são atravessados por sua marcação de gênero e peso. Quando toca em racismo, seu posicionamento é de mulher, \#pretagorda, como geralmente usa no uso de hashtags, mostrando que peso, raça e gênero costumam estar marcadamente interligados nos seus enunciados. Aliás, Érica faz uso mais frequente das hashtags como modos de construção de sentido dos seus conteúdos postados, recorrendo a palavras-chave que interseccionam suas identidades, como \#plusdosblacks (marcando peso e raça, especificamente). Érica, portanto, deixa traços discursivos constantes de que raça, gênero e peso são as três avenidas identitárias menos apartáveis no todo da sua experiência social. 
Figura 4. Publicações e marcações evidentes de peso, gênero e raça no perfil de @negritaalmeida no Instagram.
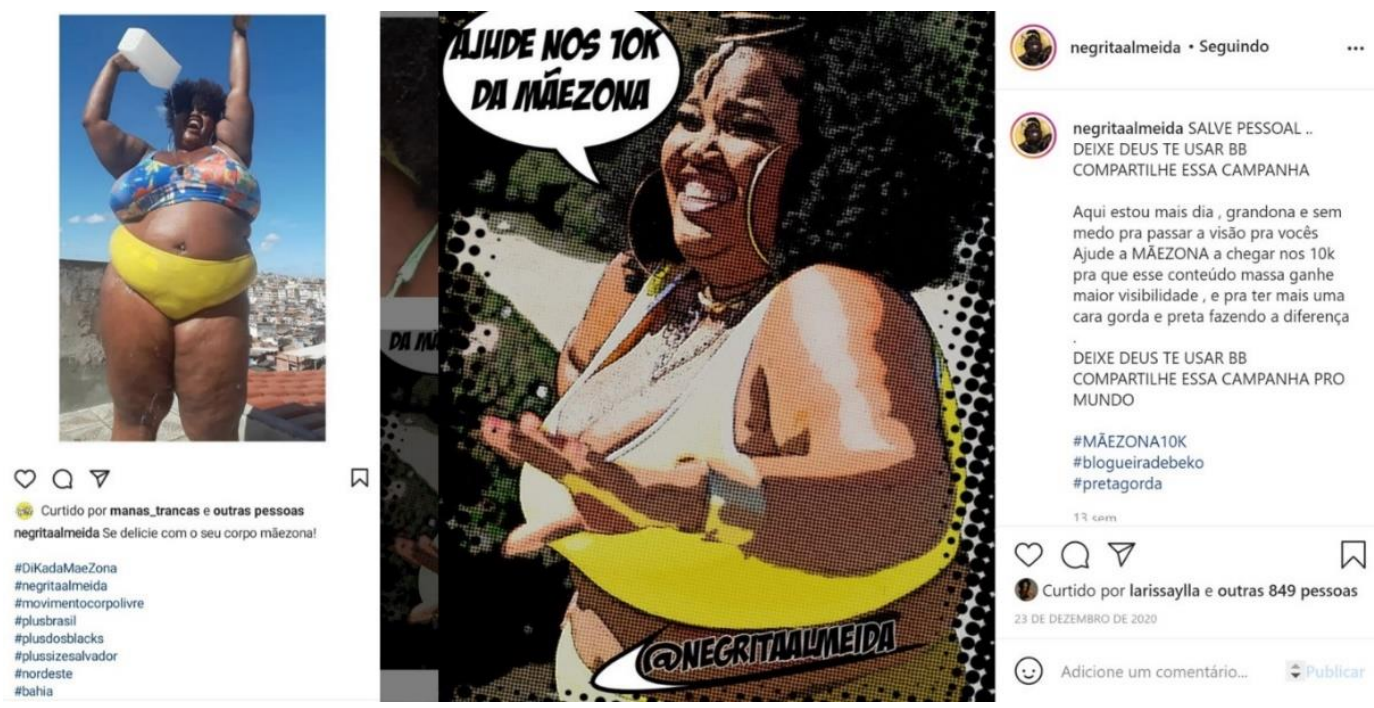

É interessante perceber que essa mobilização de peso e gênero, no perfil de Raissa (@rayneon), alcança modos de subjetivação diferenciados, até mesmo pela ausência de marcadores raciais que complexificariam seus enunciados. Raissa, a partir da sua descrição (usando expressões como Fat Fashion e "imensa de gorda"), aciona enunciados de resistência que correspondem a uma compreensão relevante sobre o que significa ser um corpo feminino gordo na sociedade ocidental. Enquanto o enunciado Fat Fashion mostra seu interesse de adentrar na perspectiva estratégica dos nichos de mercado, especificamente na moda, a expressão "imensa de gorda", utilizada comumente de forma pejorativa como forma de marcar um "corpo em excesso" (Yoshino, 2010) na cultura contemporânea, é por ela mobilizada para ressignificação da sua subjetividade enquanto mulher gorda. Ser imensa de gorda se torna, então, uma inscrição identitária que envolve completude e plenitude de ser o que é. Ao mobilizar, ainda, nos seus conteúdos, temas como sensualidade, sexo e beleza, Raissa parece reconhecer os imperativos de ser um corpo feminino e gordo, recebendo as cargas de gênero e peso que fomentam seus discurso de resistência ali.

Ainda em Raissa, a haste da geolocalização, iluminada pela expressão "do subúrbio do Rio para o mundo", poderia ser acionada a partir de outros traços audiovisuais no Instagram (o sotaque em vídeos, por exemplo). Aliás, o caráter híbrido da plataforma dificulta análises exclusivamente imagéticas ou audiovisuais, e permite que os conteúdos possam, continuamente e de modo diversificado, localizar as formações interseccionais-discursivas relevantes para o objeto analisado. Nesse sentido, os usos dialetais e as entonações marcadas na oralidade já permitiriam reconhecê-la enquanto carioca ou fluminense, no entanto não é à toa que Raissa escolhe marcar sua origem (Rio de Janeiro) na sua descrição do perfil. Ao acionar sua origem, mesmo na materialidade digital, Raissa carrega o prestígio regionalizado que coloca o Sudeste em lugar de extremo poder na geopolítica brasileira, influenciando, inclusive, na sua percepção de visibilidade e na consequente contratação por grandes marcas. Ser influenciadora digital do Rio de Janeiro, portanto, a direciona tanto para a neutralidade regional (considerando que a linguagem é reconhecida facilmente por já ter sido 
escolhida como padrão midiático), quanto para a percepção de fácil acesso (considerando que o Sudeste se configura como polo econômico e concentra boa parte do empresariado de grande porte no Brasil). Em outras palavras, ser do Sudeste, mesmo no contexto dos influenciadores digitais, é acionar sentidos de relevância, neutralidade e poder, assim como é possibilitar mais facilmente acesso a redes sociais de manutenção de privilégio.

No entanto, Raissa mobiliza o contraponto do seu poder geolocalizado quando aciona o marcador de classe (subúrbio). Embora, portanto, ser do Sudeste e do Rio de Janeiro a direcione para um lócus de privilégio na geopolítica brasileira, ser do subúrbio marca outro lugar no contexto da geopolítica das cidades, sobretudo quando se refere ao Rio de Janeiro (Do Lago, 2000). Ser do subúrbio indica marcação de classe, mesmo que não haja indicadores de renda expressos nos seus enunciados, assim como incita processos de identificação territorial e de comunidade, caros aos sujeitos à margem que sofrem os efeitos dos colonialismos internos. Ademais, ao marcar sua origem suburbana, Raissa também aciona sentidos de autenticidade, importantes para seu contexto de influenciadora digital, que também são fundamentais para estimular dinâmicas de reconhecimento identitário essenciais ao consumo; assim como citar sua formação (moda/jornalismo) tanto também dá dicas de classe quanto reivindica autoridade para a produção de conteúdo sobre corpo, body positive e moda.

No caso de Érica, a geolocalização parece ainda mais imperativa do que no perfil de Raissa, uma vez que há constantemente a marcação da origem nordestina em suas publicações (seja por meio de hashtags, como \#nordeste e \#bahia, como a partir de usos dialetais oriundos do Nordeste, da Bahia ou da cidade de Salvador, como "pega a visão”, “massa”, “véi, “receba”, "bê”. Além disso, sua diferença regional é, em conteúdos audiovisuais, inevitavelmente acionada por um sotaque não padrão. Não seria possível para Érica esquecer de mencionar a sua origem, uma vez que isso seria demandado constantemente em um ambiente desterritorializado como o meio digital, tomado por relações de poder geolocalizadas. Érica, portanto, marca sua diferença na própria oralidade e, adicionalmente, opta por deixar evidente também em conteúdos escritos e imagéticos, mostrando a importância que essa avenida identitária tem para sua subjetivação ali. Na verdade, essa marcação da diferença, no perfil de Érica, se torna estratégia comunicacional significativa: embora ser do Rio de Janeiro e do Sudeste acione o poder da padronização geolocalizada, também coloca Raissa em um lócus de homogeneização, em meio a outras influenciadoras. A diferença, destacada por Érica, poderia, portanto, trazer destaque e visibilidade. Sendo assim, somente ser de Salvador já traria a diferença que ela precisava para alcançar percepção de autenticidade, sendo, então, uma demarcação identitária relevante para sua estratégia de comunicação.

É interessante notar, ainda, no perfil de Érica (@negritaalmeida) que sua marcação de classe também é extremamente marcada por sua racialidade, sobretudo quando ela, assim como Raissa (@rayneon), demarca sua profissão para além daquele espaço, apontando que é “CEO @manas_tranças” - espaço para cuidado do cabelo crespo, tranças e penteados. Ou seja, o seu caminho profissional já foi marcado por um 
reconhecimento de sua diferença racial e de gênero, demarcando que sua classe não pode ser pensada como um lugar apartado destas categorias. Érica também traz rastros desses entrelaçamentos quando escreve na sua descrição "blogueira de beco" (equivalente a "blogueira da quebrada"), mostrando a potência dessa diferença para sua identidade ao colocá-la logo depois do seu nome.

Ser "de beco", de quebrada, sobretudo neste lugar de influenciadora digital, parece ser uma estratégia comunicacional que aponta para os conteúdos que ela vai apresentar ali. Nesse sentido, Érica prioriza essa marcação de classe até mesmo em relação a ser modelo, preta e gorda. Essa predileção, portanto, reverbera no tipo de conteúdo, na linguagem de classe (Romualdo, 1981) e nas suas escolhas discursivas, devendo ser considerada como marcador importante para a compreensão dos códigos e dos sentidos que propõe. Em um cruzamento de raça e classe, Érica então mobiliza o "pretuguês" (Gonzalez, 2018), agenciando marcadores de autenticidade e experiência que parecem reconhecer a conjuntura de marginalização da classe que pertence. A partir deste reconhecimento, Érica gerencia a exposição de si e atende ao seu lócus de subjetividade: mulher negra, gorda, nordestina e "de beco".

\section{Ethos interseccional}

Após a identificação da conjuntura simbólico-cultural que engloba as formações interseccionais-discursivas mobilizadas por @rayneon e @negritaalmeida, parte-se para a construção da silhueta da imagem de si das influenciadoras a partir do material analisado. Este momento se configura como a tentativa de reconhecer o ethos discursivo construído pelos conteúdos postados e pelas escolhas enunciativas materializadas nas imagens, na linguagem, nos produtos comunicacionais postos em circulação. Pode-se dizer, portanto, que Raissa constrói sua imagem de si como mulher gorda, ativista do movimento pela liberação do corpo gordo e pela luta contra a gordofobia, ou seja, estas são as marcações evidentes em quase todas as suas postagens. Nesse sentido, o ethos interseccional de Raissa perpassa as hastes do peso e do gênero, marcando sua "coerência expressiva" (Sá e Polivanov, 2012) dentro destes marcadores sociais da diferença.

É interessante perceber, portanto, que Raissa dificilmente se desloca desse ethos calcado pela conjuntura de peso e gênero, não somente pela sua inscrição corpórea evidenciada nas postagens, quanto por não permitir fuga temática no seu perfil. Não há até mesmo reivindicação de gênero enquanto categoria generalizada, com, por exemplo, alguma postagem mais ampla sobre feminismo. Seus conteúdos, então, marcam a sua coerência expressiva enquanto mulher gorda dentro da moda e do movimento pelo corpo livre. Até mesmo em posts patrocinados de marcas não relacionadas diretamente ao corpo gordo, quando o texto apresenta uma visão geral sobre o produto, Raissa insere um enunciado de autoaceitação e autoestima, importantes para a marcação de sua identidade enquanto influenciadora deste tipo de conteúdo ${ }^{3}$. Além disso, embora marcação de classe e geolocalização tenha sido

3 Ver: https://www.instagram.com/p/CMfpADynqOo/?utm_source=ig_web_copy_link 
mobilizada na sua descrição, não há outros acionamentos nos conteúdos que posta, revelando o direcionamento da imagem de si que prefere seguir: mulher gorda, profissional da moda e ativista do movimento body positive.

Já o ethos interseccional acionado por Érica, embora também revele coerência expressiva pela constância subjetiva que mobiliza, parece acionar a complexidade dos seus entrecruzamentos identitários de modo mais imbricado. Isto é, a cada postagem, @negritaalmeida marca sua inscrição de raça, gênero, peso, geolocalização e classe, sobretudo por meio das suas escolhas de linguagem e do uso de hashtags como modo de construção de sentido e obtenção de visibilidade a partir das suas diferenças. Em geral, seus posts, então, apresentam inscrições destas avenidas identitárias que lhe são caras, modulando cada marcador a depender do conteúdo e da temática, sem invisibilizar nenhum deles na sua constituição de si. Mesmo em publiposts ${ }^{4}$ ou postagens mais descontraídas, portanto, Érica escolhe fazer estas marcações, mais ou menos potencializadas, como forma de se inscrever em gênero, raça, peso, geolocalização ou classes .

\section{Negociações interseccionais}

Identificar negociações interseccionais na metodologia da roleta é reconhecer os impactos interacionais para a construção discursiva do objeto analisado. Nesse momento, é relevante entender de que forma Raissa e Érica negociam suas subjetividades em torno destas tensões sociais, que surgem tanto em relação ao contexto em que vivem, aos contextos interseccionais, quanto em relação aos seus contatos imediatos, ao que é demandado ali naquele espaço. Sendo assim, é interessante perceber de que forma as influenciadoras respondem aos comentários em suas postagens e de que modo essa devolutiva é fundamental para suas produções de conteúdo. Raissa e Érica, nesse contexto, costumam responder quase todas as interações, assim como, muitas vezes, transformam uma determinada devolutiva (tanto em direção ao contexto cultural interseccional que estão assujeitadas quanto para os próprios públicos localizados ali) em um conteúdo independente. É comum, por exemplo, a postagem de vídeos respondendo a perguntas gordofóbicas que comumente são endereçadas a elas, como forma de marcar suas posições de resistência e empoderamento ${ }^{6}$. Nesse sentido, como forma de garantir seus lugares na plataforma digital e no contexto das influenciadoras do movimento Body Positive, as duas utilizam o engajamento e as interações como forma de sustentação das suas

\footnotetext{
4 Publipost em que @negritaalmeida reivindica sua marcação de gênero, peso e raça: https://www.instagram.com/p/CD_oA6UJ8JL

${ }^{5}$ É comum ver algumas de classe, como \#donadalaje, em grande parte dos seus posts: https://www.instagram.com/p/CGNgxKVDMJI
}

${ }^{6}$ Ver: https://www.instagram.com/p/CFVYZX7n8SA/?utm_source=ig_web_copy_link 
identidades, a partir, sobretudo, da percepção de que a negociação de seus códigos de autenticidade devem ser, também, interseccionais.

\section{CONSIDERAÇÕES FINAIS}

O método da roleta interseccional é uma tentativa de firmar, em estudos comunicacionais, a complexidade dos sujeitos e dos objetos dentro de uma conjuntura sociocultural. Reconhecer os atravessamentos identitários, portanto, é o primeiro passo para a compreensão dos processos de subjetivação, mas não é suficiente para a teorização sobre dinâmicas de opressão que emergem destas encruzilhadas, não somente porque são estruturas relativamente autônomas, mas também em virtude das especificidades das situações de interação. Dentro dessa perspectiva, a roleta interseccional serviria à pesquisa em Comunicação como um caminho metodológico em direção a olhares epistemológicos mais ampliados, no sentido da heterogeneidade dos objetos de análise, e mais circunscritos, no sentido da delimitação das influências das materialidades e das nuances situacionais.

Reivindica-se aqui, portanto, a necessidade de atenção importante a dinâmicas de opressão ainda negligenciadas nos estudos interseccionais em Comunicação, como aquelas que não se restringem a gênero, raça e classe, entendendo que outras avenidas identitárias, como geolocalização, sexualidade, deficiência, idade e peso, não somente são marcadores da diferença fundamentais para a constituição do sujeito como são, muitas vezes, estruturas que complexificam as experiências sociais e as escolhas em gênero, raça e classe. Nesse sentido, atesta-se aqui o alinhamento da proposta ao cerne do conceito de interseccionalidade, que versa sobre a não hierarquização das opressões e o direcionamento do olhar epistemológico para a identificação e contextualização de como estas interseções deslocam o objeto analisado para lugares subjetivos singulares.

No esboço analítico aqui empreendido, portanto, pôde-se perceber que as encruzilhadas identitárias podem direcionar as escolhas discursivas e as estratégias comunicacionais, modulando as intensidades das estruturas sobre os corpos e sobre os sujeitos a depender dos contextos situacionais e interacionais. Se, no caso dos perfis das influenciadoras digitais em questão, a visibilidade e a quantidade de seguidores pode ser uma problemática importante para análises sobre processos de influência e construção de rede no contexto digital (podendo ser percebidas a partir de olhar interseccional), aqui o estudo se debruçou sobre os modos de produção de si na materialidade do Instagram, assim como as estratégias comunicacionais que podem ecoar processos de subjetivação assujeitados a dinâmicas potentes de opressão. A roleta interseccional, portanto, tenta auxiliar as análises comunicacionais na busca pela compreensão destas nuances, destas modulações e subordinações que acometem sujeitos em interação, entendendo que o direcionamento à complexidade pode ser o caminho mais coerente ao projeto teórico do conceito de interseccionalidade. 


\section{REFERÊNCIAS}

AIRES, A. De gorda à plus size: a moda do tamanho grande. São Paulo: Estação das letras e cores, 2019

ANZALDÚA, Gloria. Borderlands/La Frontera: The New Mestiza. San Francisco: Aunt LuteBooks, 1987.

BEAUVOIR, Simone. O segundo sexo. Nova Fronteira, 2014.

BUTLER, Judith. Problemas de gênero: Feminismo e subversão de identidade. Rio de Janeiro: Civilização Brasileira, 2010.

CARRERA, F. Roleta interseccional: proposta metodológica para análises em Comunicação. E-Compós. https://doi.org/10.30962/ec.2198, 2020

CARNEIRO, Sueli. Gênero Raça e Ascensão Social. Revista Estudos Feministas, v. 3, n. 2, p.544, 1995.

CASTRO, Gisela GS. Precisamos discutir o idadismo na comunicação. Comunicação \& educação, v. 20, n. 2, p. 101-114, 2015.

COLLINS, Patricia Hill. Se perdeu na tradução? Feminismo negro, interseccionalidade e política emancipatória. Parágrafo, v. 5, n. 1, p. 6-17, 2017.

COLLINS, Patricia Hill. Black feminist thought: Knowledge, consciousness, and the politics of empowerment. Nova York: Routledge, 2002.

CRENSHAW, Kimberlé. Demarginalizing the intersection of race and sex: A black feminist critique of antidiscrimination doctrine, feminist theory and antiracist politics. u. Chi. Legal f., p. 139, 1989.

CWYNAR-HORTA, Jessica. The commodification of the body positive movement on Instagram. Stream: Culture/Politics/Technology, v. 8, n. 2, p. 36-56, 2016.

D’ANTINO, Maria Eloísa Famá. Deficiência e a mensagem reveladora da instituição especializada: Dimensões imagética e textual. Tese IP/USP. São Paulo, 2001.

DEVULSKY, A. Colorismo. Coleção Feminismos plurais. $1^{\text {a }}$ edição, 2021

DO LAGO, Luciana Corrêa. Desigualdades e segregação na metrópole: o Rio de Janeiro em tempo de crise. Observatório IPPUR/UFRJ-FASE, 2000.

DO NASCIMENTO, Abdias. O genocídio do negro brasileiro: processo de um racismo mascarado. Editora Perspectiva SA, 2016.

FERNANDES, Ana Paula; DENARI, Fatima Elisabeth. Pessoa com deficiência: estigma e identidade. Revista da FAEEBA, v. 26, n. 50, p. 77, 2017.

FOUCAULT, Michel. História da Sexualidade I: a vontade de saber. Rio de Janeiro: Edições Graal, 1988. 
GELEHRTER, Ruth. Precisamos perguntar o que os idosos desejam. Entrevista. Radis, $\mathrm{n}^{\circ}$ 216,2020

GOFFMAN, Erving. Estigma: notas sobre a manipulação da identidade. Tradução: Mathias Lambert, v. 4, 1988.

GONZALEZ, Lelia. Por um feminismo afrolatinoamericano. Revista Isis Internacional, Santiago, v. 9, p. 133-141, 1988.

GONZALEZ, Lelia. A Juventude Negra Brasileira. In: GONZALEZ, Lelia. Primavera para as rosas negras: Lélia Gonzalez em primeira pessoa. São Paulo: Diáspora Africana, 2018.

GROHMANN, Rafael do Nascimento. As classes sociais na comunicação: sentidos teóricos do conceito. 2016. Tese de Doutorado. Universidade de São Paulo.

KUHN, Martin. Síndrome de Down e mídia: uma análise da questão do estigma na propaganda institucional. ACTA Científica - Ciências Humanas - $2^{\circ}$ Semestre - 2005

MAGALHÃES, Rita; CARDOSO, Ana Paula. A pessoa com deficiência e a crise das identidades na contemporaneidade. Cadernos de Pesquisa, v. 40, n. 139, p. 45-61, 2010.

MARANHO, Elisa Peres; CONTIERO, Lucinéia; DE MARINGÁ, Cesumar-Centro Universitário. O riso na publicidade: uma estratégia de luta. In: IX Congresso de Ciências da Comunicação na Região Sul-Intercom. São Paulo. 2008.

MARTINS, Vírnia; CARRERA, Fernanda. Body positive no Instagram. Razón y Palabra, v. 24, n. 109, 2020.

MURDOCK, Graham. Comunicação contemporânea e questões de classe. Revista MATRIZes, São Paulo, v. 2 n. 2, p.31-56, 2009.

PALACIOS, A. Velhice, palavra quase proibida; terceira idade, expressão quase hegemônica: apontamentos sobre o conceito de mudança discursiva na publicidade contemporânea. XX Encontro da Associação Portuguesa de Linguisitca (APL). Lisboa, 2004

PELINSON, Fabiana. Usos dialetais e preconceito linguístico na telenovela "joia rara". InterteXto, v. 9, n. 1, 2016.

QUIJANO, Anibal. Colonialidade, poder, globalização e democracia. Novos rumos, v. 37, n. 17, p. 4-28, 2002.

ROMUALDO, Jonas A. Linguagem e estratificação social. Cadernos de Estudos Lingüísticos, v. 2, p. 11-22, 1981.

SÁ, Simone; POLIVANOV, Beatriz. Auto-reflexividade, coerência expressiva e performance como categorias para análise dos sites de redes sociais. Contemporânea, v. 10, n. 3, p. 574-596, 2012.

SCHUCMAN, L. V. Entre o encardido, o branco e o branquíssimo: raça, hierarquia e poder na construção da branquitude paulistana. 2012. Tese (Doutorado) - Universidade de São Paulo, São Paulo, 2012. 
VIEIRA, T. R. (org) Minorias Sexuais: direitos e preconceitos. 1 ed. Brasília: Editora Consultex, 2012.

YOSHINO, NL. A normatização do corpo em excesso [tese]. Campinas: Faculdade de Ciências Médicas Universidade Estadual de Campinas; 2010. 